\title{
0930 FINDINGS OF A INJURY SURVEILLANCE PROGRAMME DONE IN A RURAL DISTRICT SETUP IN INDIA
}

A Jayaram*, G Gururaj, M S Rajanna, P Venkatesh Correspondence: Sri Siddhartha Medical college, Agalkote, B.H Road, Tumkur 572107, India

10.1136/ip.2010.029215.930

Introduction With many stakeholders in the collection of information on injuries it is very essential to have an effective surveillance system that combines data from different sources. Injury surveillance programmes in the developing world is a rarity. Hence the exact burden, types and strategies for prevention of injuries in the developing countries like is India is lacking. An initiative to start an injury surveillance programme was taken up by the WHO collaborating centre at National Institute of Mental health and Neurosciences, Bangalore.

Aim and Objectives To present the findings of the injury surveillance programme done in representative health institutions in a rural district setup in India.

Methodology Injury surveillance data collected from casualty departments of a rural district hospital, Medical College Hospital, 2 community and 3 primary health centres were collected for a period of more than 2 years. A standardised format developed by the Bangalore Injury surveillance programme was used for collecting the surveillance data. The data was entered into Epi Info and later analysed.

Results A total of 2146 injuries were analysed. Road traffic injuries constituted the major burden accounting for more than $50 \%$ of all injuries recorded. The second commonest cause of injury was assault (20\%) followed by poisoning $(12 \%)$. The distribution of injuries with regard to intent, severity, first-aid received, mode of transport used to reach the hospital and number of hospital visited were analysed. The road traffic injuries with regard to the type of roads and road user category were analysed. The findings will be presented in the conference. 